\title{
Discordant creatine kinase and cardiac troponin T in the workup of acute coronary syndrome
}

\author{
Jamil Kanji, MD, BSc(Hons); ${ }^{*}$ Jerome Fan, $\mathrm{MD}^{\dagger}$
}

\section{ABSTRACT}

A 55-year-old man presented to the emergency department (ED) following 2 episodes of typical cardiac chest pain and nonspecific electrocardiogram findings. His serial cardiac marker assays revealed an elevated total creatine kinase (CK) and 2 negative cardiac troponin levels. Because of a high clinical suspicion of acute coronary syndrome, a total creatine kinase MB mass was obtained and found to be elevated. Subsequent cardiac angiography demonstrated a significantly flow-limiting coronary artery lesion, and stenting was performed. This case demonstrates that simultaneous CK and troponin measurements may have utility in selected ED patients with chest pain. The interpretation of discordant CK and troponin levels is discussed.

Keywords: myocardial infarction, troponin, creatine kinase, diagnostic testing

\section{RÉSUMÉ}

Un homme de 55 ans s'est présenté à l'urgence après 2 épisodes de douleurs thoraciques cardiaques et des résultats d'électrocardiogramme non spécifiques. Le dosage en série de marqueurs cardiaques a révélé un taux élevé de créatine kinase totale $(C K)$ et 2 résultats négatifs pour la troponine cardiaque. En raison d'une forte suspicion clinique de syndrome coronarien aigu, on a fait le dosage de la créatine kinase MB masse, et les taux ont été jugés élevés. Une angiographie cardiaque subséquente a révélé une lésion de l'artère coronarienne limitant le flux de façon significative, et un tuteur a été posé. Ce cas illustre que le dosage simultané de la CK et de la troponine peut être utile chez certains patients se présentant à l'urgence avec des douleurs thoraciques. Cet article discute l'interprétation des taux discordants de CK et de troponine.

\section{INTRODUCTION}

The risk stratification of chest pain in the emergency department (ED) involves obtaining historical information and performing a physical examination, along with obtaining serial electrocardiograms (ECGs) and cardiac biomarkers. The current Canadian standard of care is to use cardiac troponin assays in this evaluative process. In recent studies, the sensitivities of cardiac troponin I (cTnI) and cardiac troponin $\mathrm{T}(\mathrm{c} T \mathrm{~T} \mathrm{~T})$ have been reported to range between $72 \%-95 \%$ and $84 \%-89 \%$, respectively. ${ }^{1-3}$ In the context of the universal definition of a myocardial infarction (MI), an increased troponin is a value exceeding the 99th percentile of a normal reference population. The detection of a rise and/or fall of such biomarkers is essential to the diagnosis of an acute MI. ${ }^{4}$ For largely historical reasons, many centres still include total creatine kinase (CK) levels in their workup protocols for chest pain. On occasion, there are discordant findings between these 2 tests. The optimal management in these scenarios is unclear. We present a case in which discordant $\mathrm{CK}$ and troponin levels led to the diagnosis of non-ST elevation acute coronary syndrome (ACS) requiring percutaneous cardiac intervention and stent placement.

\section{CASE REPORT}

A 55-year-old man presented to the ED following 2 episodes of retrosternal chest pressure associated with diaphoresis and light-headedness. He was rapidly triaged, and was pain-free when seen by the emergency physician. Each episode of chest pain had been brought on by walking up a flight of stairs. The first episode lasted 10 minutes and was relieved with rest. The second episode began when the patient attempted to go up several more flights. The pain persisted for 45 minutes despite the patient's resting, although it had resolved on

From the *Department of Internal Medicine, McMaster University, Hamilton, Ont., and the †Division of Emergency Medicine, Hamilton Health Sciences, McMaster University, Hamilton, Ont.

Submitted Jun. 26, 2008; Revised May 31, 2009; Accepted Jul. 26, 2009

This article has been peer reviewed.

CJEM 2010;12(1):64-8 
the patient's arrival at the ED after administration of $2 \mathrm{mg}$ of intravenous morphine by paramedics. Neither episode was associated with classic pain radiation, nausea, vomiting, orthopnea, back pain, syncope or presyncope.

Physical examination revealed an afebrile mildly diaphoretic man in no acute distress with blood pressures of $172 / 102 \mathrm{~mm} \mathrm{Hg}$ in the right arm and $167 / 97 \mathrm{~mm} \mathrm{Hg}$ in the left arm. He had a regular heart rate of 88 beats $/ \mathrm{min}$, a respiratory rate of 18 breaths/min and $99 \%$ oxygen saturation on room air. The remainder of the physical examination was unremarkable. An ECG done during triage revealed normal sinus rhythm, a left anterior fasicular block and an incomplete right bundle branch block with no significant ST or T-wave changes. No previous ECGs were available for comparison.

The patient's history was significant for suspected MI 15 years earlier. His cardiovascular risk factors included a 25 pack-year history of smoking (still smoking), hypertension and a family history of coronary artery disease. He intermittently took acetylsalicylic acid (ASA) $81 \mathrm{mg}$, and was on no other medications. He denied use of alcohol or recreational drugs. Review of systems was unremarkable. Self-reported exercise tolerance was more than 6 blocks on level ground.

Treatment with ASA $160 \mathrm{mg}$ by mouth and supplemental oxygen was initiated and blood was drawn for laboratory testing. The patient remained free of chest pain. The complete blood count, electrolytes, creatinine, international normalized ratio, partial thrombin time and chest radiography were normal. Total CK at 1 hour after onset of chest pain was $17.87 \mu \mathrm{kat} / \mathrm{L}$ (normal $<3.76 \mu \mathrm{kat} / \mathrm{L}$ ) and $\mathrm{c} T \mathrm{n} T<0.01 \mu \mathrm{g} / \mathrm{L}$ (normal $0.03 \mu \mathrm{g} / \mathrm{L}$ ).

On reassessment, the patient was comfortable with no complaints of recurrent chest pain, and the physical examination and repeat ECG were unchanged from before. Repeat blood tests, drawn 8 hours after the initial set, revealed a normal cTnT of $<0.01 \mu \mathrm{g} / \mathrm{L}$ and elevated $\mathrm{CK}$ of $14.28 \mu \mathrm{kat} / \mathrm{L}$. Because of the history, risk factors and elevated $\mathrm{CK}$, the treating physician initiated therapy for presumed ACS with daily ASA $(81 \mathrm{mg})$, clopidogrel (75 mg) and fondaparinux $(2.5 \mathrm{mg})$. A computed tomography angiogram of the chest revealed no evidence of aortic dissection with normal caliber of the great vessels. The medical biochemist was contacted for permission to perform serial CK-MB mass assays (normally only c Tn'T is carried out).

The patient's initial CK-MB mass assay was positive at $29 \mu \mathrm{g} / \mathrm{L} 7$ hours after presentation (normal $<6.73 \mu \mathrm{g} / \mathrm{L}$ ). Other relevant markers were also elevated: aspartate aminotransferase was $0.73 \mu \mathrm{kat} / \mathrm{L}($ normal $<0.58 \mu \mathrm{kat} / \mathrm{L})$ and lactate dehydrogenase isoenzymes was $3.79 \mu \mathrm{kat} / \mathrm{L}$ (normal $<3.67 \mu \mathrm{kat} / \mathrm{L}$ ).

As the patient required follow-up of serial cardiac markers and cardiac risk stratification, he was admitted to hospital by the internal medicine service with the diagnosis of acute coronary syndrome. Three serial cTnT measurements (every $8 \mathrm{~h}$ ) remained negative. Repeat CK-MB values were 23, 22, 21, 20, and $17 \mu \mathrm{g} / \mathrm{L}$ (every $6 \mathrm{~h}$ ) and $\mathrm{CK}$ values were $14.28 \mu \mathrm{kat} / \mathrm{L}, 9.79 \mu \mathrm{kat} / \mathrm{L}$, $8.32 \mu \mathrm{kat} / \mathrm{L}, 7.60 \mu \mathrm{kat} / \mathrm{L}$ and $6.51 \mu \mathrm{kat} / \mathrm{L}$ (also every $6 \mathrm{~h}$ ). Electrocardiograms were repeated several times throughout the night with no changes from baseline.

The patient was subsequently referred to the cardiology service. An angiogram revealed a long, hazy lesion in the left anterior descending (LAD) artery after the first diagonal branch (Fig. 1A). Other arteries had only mild irregularities. Aortic pressure was $96 / 40 \mathrm{~mm} \mathrm{Hg}$, left ventricular pressure was $90 \mathrm{~mm} \mathrm{Hg}$ and left-ventricular end-diastolic pressure was $14 \mathrm{~mm} \mathrm{Hg}$. The patient had normal left ventricular function with a minimal wall motion abnormality. Fractional flow reserve (FFR) measurement with intracoronary adenosine of the LAD lesion was 0.75 , indicating the lesion was hemodynamically significant. A bare metal stent was deployed in the LAD plaque decreasing the stenosis to $0 \%$ (Fig. 1B). Combined ASA and clopidogrel for 12 months, followed by lifelong daily ASA was recommended. Before discharge, therapy with metoprolol (titrated to the patient's heart rate), ramipril and atorvastatin was also initiated.

\section{DISCUSSION}

Since the definition of acute MI was changed to include a rise in either CK-MB or cTn as part of the criteria, discordance between the results of various cardiac biomarkers has become increasingly recognized and studied. ${ }^{4}$ The prevalence of such discordance ranges between $7 \%$ and $28 \% .^{5-7}$ Discordant biomarker results raise important questions regarding the prognosis, diagnosis and management of such patients.

The reported prognosis of patients with discordant cardiac biomarkers varies based on the individual study and timing of follow-up. One study by Yee and colleagues $^{6}$ of 542 patients with ACS compared short- and long-term outcomes in patients categorized as CK$\mathrm{MB}+/ \mathrm{cTnI}-$ with those who had entirely negative biomarkers (CK-MB-/cTnI-). All marker determinations were made on admission to hospital. The follow-up rate at 6 months was $82 \%$. Among cTnI negative patients, 
$21.6 \%$ were CK-MB positive. Those in the CK$\mathrm{MB}+/ \mathrm{cTnI}-$ group had significantly higher rates of readmission to hospital for cardiac disease $(36 \%$ v. $23 \%$, $p=0.03)$. At the 6-month follow-up, there was a significantly higher rate of the composite outcome of death, re-admission to hospital for cardiac disease, stroke and acute $\mathrm{MI}$ in the CK-MB+/cTnI- group (odds ratio [OR] 1.86, 95\% confidence interval [CI] 1.14-3.03). The proportion of individual and composite negative outcomes was found to be increased when the analysis was restricted to patients presenting with non-ST elevation ACS, such as the patient in the present case. Many of the CK-MB+/cTnI- patients in this study would have been categorized as low-risk if CK-MB measurements had been omitted.

A second study evaluating the frequency and outcomes of discordant cardiac marker results reported the OR for in-hospital mortality in a CK-MB+/cTn- population at 1.02 (95\% CI 0.75-1.38) when compared with CK-MB-/cTn- patients. ${ }^{7}$ This was a study carried out in 29357 patients presenting with non-ST elevation ACS as part of the international CRUSADE study.? Values for CK-MB and cTnT or cTnI were evaluated from peak measurements within 36 hours of patient presentation. The authors concluded that an isolated positive CK-MB had limited prognostic value. The corresponding mortality rates among biomarker discordant groups were found to be similar in the various groups: $2.7 \%$ (CK-MB-/cTn-), 3.0\% (CK-MB+/cTn-) and $4.6 \%(\mathrm{CK}-\mathrm{MB}+/ \mathrm{cTn}+)$. The proportion of discordant results among this cohort of patients was $28 \%(10 \%$ with $\mathrm{CK}-\mathrm{MB}+/ \mathrm{c}$ Tn-). ${ }^{7}$ The main difference between this study and the one discussed previously was the end point assessment (i.e., 1-time in-hospital mortality evaluation as opposed to 6-month follow-up). The authors concluded that elevation of CK-MB in the setting of negative $\mathrm{c} T \mathrm{n}$ was a more sensitive marker for risk over the long term, rather than in the acute setting. ${ }^{6,7}$ Nonetheless, a positive CK-MB in the setting of a negative cTnT still appears to be an independent marker for stratifying patients at higher risk in terms of morbidity and mortality in the long term.

Explanations of the CK-MB+/cTnT- discordance in our patient include both the timing of marker testing in relation to symptom onset, as well as a falsenegative cTnT test. As our patient had several negative serial c $\mathrm{Tn} T$ measurements, the first reason is unlikely. In an analysis by Newby and coworkers ${ }^{7}$ the cTnT was used more frequently among patients in the CK-MB+/cTn- group. The study by Yee and colleagues used only cTnT for cardiac evaluation. Previous studies comparing the $2 \mathrm{cTn}$ assays concluded that cTnI performs slightly better in ACS with sensitivities of $100 \%$ for acute $\mathrm{MI}$ and $36 \%$ for unstable
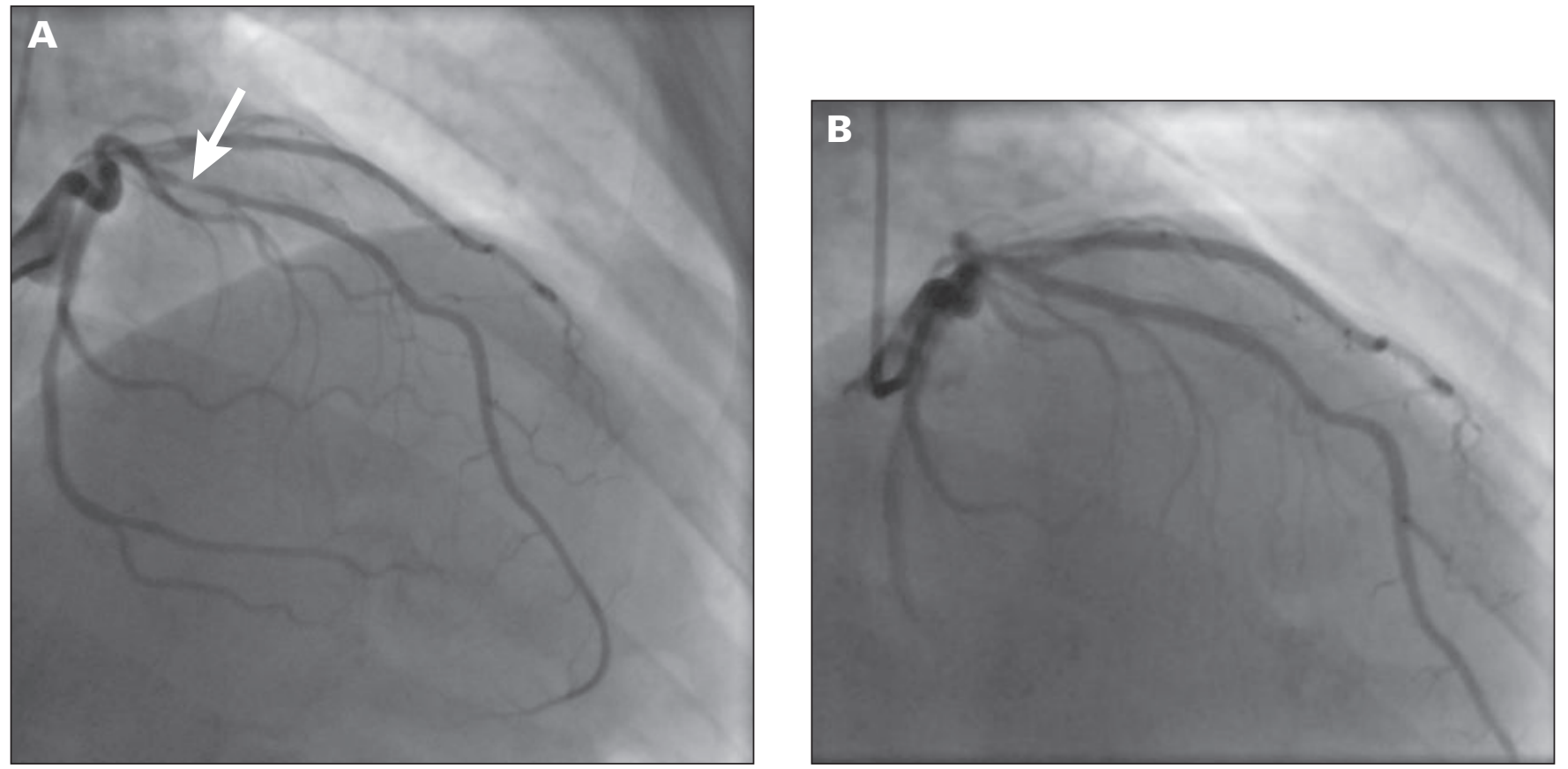

Fig. 1. Angiogram revealing a $60 \%-70 \%$ lesion after the first diagonal branch of the left anterior descending artery (arrow). The diagonal branch itself has a $40 \%$ lesion at its origin (A). After insertion of bare metal stent, there is no residual stenosis in the aforementioned area (B). 
angina. ${ }^{8,9}$ For MI, c'TnI is also more specific than cTnT. A recent study by McCann and coworkers ${ }^{3}$ evaluated the utility of cTnT and found it to have sensitivities of $55 \%, 84 \%$ and $89 \%$ when the patient presented to the ED less than 4 hours, 4-8 hours and 8-12 hours after the onset of chest pain, respectively. Unfortunately, our institution does not routinely perform tests of cTnI levels and we were unable to obtain them for comparison. However, given that cTnI can outperform cTnT in a small number of patients, we believe it is likely that the negative serial cTnT measurements observed were false negatives.

In an analysis of a prospective registry for the EMCREG-i $i^{*}$ tr ACS,${ }^{10}$ the results of 8769 patients also presenting with possible non-ST elevation ACS were reviewed. The objective of this study was to evaluate the association between several pairs of discordant cardiac biomarker combinations. The authors found that the unadjusted OR for ACS in a patient with CK$\mathrm{MB}+/ \mathrm{cTn}$ - discordance was 2.17 (95\% CI 1.72-2.75). This study evaluated patients with either type of troponin. Interestingly, patients in the $\mathrm{CK}-\mathrm{MB}+/ \mathrm{CK}+$ group of this study had an OR of 4.36 (95\% CI 3.64$5.23)$, which was double that of the CK-MB+/cTngroup for ACS. ${ }^{10}$ The authors did not specify whether this second group also had a simultaneously elevated cTn value or only isolated CK and CK-MB elevations.

Given the above data and the convincing history that our patient provided, our suspicion for ACS was quite high. Despite the elevations found in his CK and CK$\mathrm{MB}$, there was not enough evidence to unequivocally establish a diagnosis of non-ST elevation MI. The patient's angiogram revealed normal systolic function with only minimal wall motion abnormality. However, the patient did have a significant stenotic lesion, as defined by the FFR, which is a measure of the physiologic importance of stenotic lesions in coronary arteries. It is calculated as the ratio of the maximum blood flow in a stenotic artery to that of normal flow. The normal FFR in a nonstenotic artery is defined as 1.0. An FFR below 0.80 has a $90 \%$ accuracy in identifying ischemiacausing coronary stenoses. ${ }^{11}$

Studies suggest that a discrepancy exists between the administration of evidence-based therapies to patients with discordant and nondiscordant cardiac biomarkers. ${ }^{7}$ Newby and colleagues found that CK-MB+/cTnpatients were less likely to receive a $\beta$-blocker on discharge (OR 1.02, 95\% CI 0.89-1.17) compared with CK-MB-/cTn+ (OR 1.34, 95\% CI 1.20-1.51) or CK$\mathrm{MB}+/ \mathrm{cTn}+(\mathrm{OR} 1.62,95 \%$ CI 1.45-1.80) patients. The
$\mathrm{CK}-\mathrm{MB}+/ \mathrm{cT}$ - group was also more likely to undergo percutaneous coronary intervention within 24 hours when compared with other groups (OR 2.11, 95\% CI 1.65-2.68). This finding is also supported by registry studies in which AMI patients were found to be more likely to receive evidence-based therapies when compared with patients with unstable angina. ${ }^{12}$

\section{CONCLUSION}

Although uncommon, the possibility of discordance between CK-MB and cTn results has become increasingly recognized. There is data to support both shortand long-term prognostic implications in patients with CK-MB and cTn discordant results. The likelihood that these patients will have an ACS is higher than for those who have entirely negative serial biomarkers, and, as such, they should likely receive therapy recommended by current evidence-based guidelines. In light of these findings, we believe diagnostic algorithms for non-ST elevation MI ACS should be re-examined to determine how simultaneous biomarker measurement can be efficiently used to identify patients at higher risk for poor outcomes, without indiscriminately obtaining both markers on all patients.

Acknowledgements: We thank Dr. Juan Guzman and Dr. Sebastian Ribas at McMaster University for their help with acquiring the cardiac angiogram images.

Competing interests: None declared.

\section{REFERENCES}

1. Apple FS, Smith SW, Pearce LA, et al. Assessment of the multiple-biomarker approach for the diagnosis of myocardial infarction in patients presenting with symptoms suggestive of acute coronary syndrome. Clin Chem 2009;55:93-100.

2. Saiki A, Iwase M, Takeichi Y, et al. Diversity of the elevation of serum cardiac troponin I levels in patients during their first visit to the emergency room. Circ J 2007;71:1458-62.

3. McCann CJ, Glover BM, Menown IBA, et al. Novel biomarkers in early diagnosis of acute myocardial infarction compared with cardiac troponin T. Eur Heart 7 2008;29: 2843-50.

4. Thygesen K, Alpert JS, White HD, et al. Universal definition of myocardial infarction. Circulation 2007;116:2634-53.

5. Storrow AB, Lindsell CJ, Han JH, et al. Discordant cardiac biomarkers: frequency and outcomes in emergency department patients with chest pain. Ann Emerg Med 2006;48:660-5.

6. Yee KC, Mukherjee D, Smith DE, et al. Prognostic significance of an elevated creatine kinase in the absence of an elevated troponin I during an acute coronary syndrome. $A m$ J Cardiol 2003;92:1442-4. 
7. Newby LK, Roe MT, Chen AY, et al. Frequency and clinical implications of discordant creatine kinase-MB and troponin measurements in acute coronary syndromes. $7 \mathrm{Am}$ Coll Cardiol 2006;47:312-8.

8. Hamm CW, Goldmann BU, Heeschen C, et al. Emergency room triage of patients with acute chest pain by means of rapid testing for cardiac troponin T or troponin I. $N$ Engl 7 Med 1997;337:1648-53.

9. Tucker JF, Collins RA, Anderson AJ, et al. Early diagnostic efficiency of cardiac troponin I and troponin $\mathrm{T}$ for acute myocardial infarction. Acad Emerg Med 1997;4:13-21.

10. Storrow AB, Lindsell CJ, Han JH, et al. Discordant cardiac biomarkers: frequency and outcomes in emergency department patients with chest pain. Ann Emerg Med 2006;48:660-5.

11. Tonino PAL, De Bruyne B, Pijls NHJ, et al. Fractional flow reserve versus angiography for guiding percutaneous coronary intervention. N Engl J Med 2009;360:213-24.

12. Kramer JM, Newby LK, Chang W-C, et al. International variation in the use of evidence-based medicines for acute coronary syndrome. Eur Heart 7 2003;24:2133-41.

Correspondence to: Dr. Jerome Fan, Division of Emergency Medicine, McMaster University, 50 Charlton Ave. E., St. Joseph's Healthcare, Hamilton ON L8N 4A6; jeromefan1976@gmail.com

\section{RENSEignementS AUX LECTEURS}

\begin{abstract}
Abonnement et ventes
Le Journal canadien de la médecine d'urgence (JCMU) est offert à titre gracieux aux membres de l'Association canadienne des médecins d'urgence (ACMU) dont la cotisation est à jour; les autres peuvent s'abonner annuellement. Tarifs pour 2010 (6 numéros) : Abonnements au Canada : individuels 225 \$, établissements 399 \$; aux États-Unis et ailleurs : individuels 254 \$US, établissements 449 \$US. Communiquez avec le bureau de l'ACMU au $800463-$ 1158. Exemplaire unique d'un numéro de l'année en cours $50 \$$; anciens numéros 50 \$ (sujet à disponibilité). On doit faire le paiement à l'ordre de l'ACMU en argent canadien ou américain. Les cartes VISA et MasterCard sont également acceptées.
\end{abstract}

\section{Changement d'adresse}

Nous demandons un avis de 6 à 8 semaines afin d'assurer un service ininterrompu. Veuillez faire parvenir votre adresse postale actuelle, votre nouvelle adresse et la date à laquelle elle doit entrer en vigueur à : cjem@caep.ca ou faites parvenir un fax au 613 523-0190.

\section{Tirés à part}

Des tirés à part d'articles du JCMU sont disponibles en quantités minimales de 50. Pour des renseignements sur les commandes, veuillez communiquer avec la coordonnatrice des tirés à part, 800 663-7336 ou 613 731-8610 x2110, fax 613 565-7704, janis.murrey @ cma.ca

\section{Disponibilité électronique}

Le JCMU est disponible sur le site Web de l'ACMU (cjemonline.ca).

\section{Répertoriage}

Le JCMU est répertorié par MEDLINE/PubMed, EMBASE,
CINAHL, International Pharmaceutical Abstracts, BIOME/ OMNI, Scirus, Cochrane Prehospital and Emergency Health Field et Pubs Hub.com.

\section{Droits d'auteur et permissions}

Le droit d'auteur de tout le matériel appartient à l'ACMU ou à ses concédants. Vous pouvez en général reproduire ou utiliser le matériel trouvé dans ce journal seulement à condition de respecter la loi canadienne sur le droit d'auteur et d'accorder le crédit à l'auteur original. Pour photocopier le document ou le reproduire autrement, veuillez communiquer avec la Canadian Copyright Licensing Agency (Agence canadienne d'octroi des licences pour le droit d'auteur) (Access Copyright) au 800893 5777 , accesscopyright.ca. Pour toute autre utilisation, y compris la réédition, la redistribution, le stockage dans un système de consultation ou la transmission sous quelque forme ou par quelque moyen que ce soit, veuillez communiquer avec Andrea Schaffeler, Rédactrice administrative par intérim, Canadian Journal of Emergency Medicine, 628 Cowan Circle, Pickering ON L1W 3K7, cjem@rogers.com

\section{Instructions pour les auteurs}

Visitez le www.cjem-online.ca.

\section{Advertising}

Annonces classées : Communiquez avec Bev Kirkpatrick ou Deborah Rodd, 7CMU, 1867, prom. Alta Vista, Ottawa ON K1G 5W8; $800663-7336$ ou $613731-8610$ x2127/2314; fax $613565-7488$; advertising@cma.ca. Veuillez consulter la section des Annonces classées du Journal pour tout renseignement sur les tarifs. Annonces publicitaires : Communiquez avec Deborah Woodman (voir l'information précédente); x2159. 